\title{
ARTICULAÇÃO DO PROGRAMA MAIS EDUCAÇÃO COM O PROJETO POLÍTICO-PEDAGÓGICO: CONTRIBUIÇÕES NA FORMAÇÃO DOS ALUNOS
}

http://dx.doi.org/10.5902/2318133824560

\author{
Fernanda Luiza Simon \\ Escola Estadual de Educação Básica Estado de Goiás, Brasil. \\ Glades Tereza Felix \\ Universidade Federal de Santa Maria, Brasil.
}

\begin{abstract}
Resumo
Este texto é um recorte da monografia realizada no Curso de Especialização em Gestão Educacional, relacionada ao Programa Mais Educação e ao projeto político-pedagógico. No referencial teórico partimos da ideia pioneira de educação integral na concepção de Anísio Teixeira, além dos fundamentos de Lück $(2000,2006)$, Veiga (2004) e Gadotti (2000). Objetivouse analisar e identificar de que modo a união entre esses dois pontos pode interferir de modo qualitativo na formação dos estudantes. Nos resultados considera-se que mesmo não encontrando uma articulação entre o PME e o PPP da escola, o Programa tem aceitação na comunidade escolar, cumprindo o papel que se propõe: atender as crianças em situação de vulnerabilidade e acompanhamento da aprendizagem escolar.

Palavras-chave: Programa Mais Educação, projeto político-pedagógico, educação integral.
\end{abstract}

\section{ARTICULATION PROGRAM MORE EDUCATION WITH POLITICAL AND EDUCATIONAL PROJECT: CONTRIBUTIONS IN FORMATION OF PUPILS}

\section{Abstract}

This text is an excerpt of the monograph held at Specialization in Educational Management which is related to the More Education Program and political-pedagogical project. In the theoretical framework, we start from the pioneering idea of Integral Education in designing Teixeira, beyond the fundamentals of Lück (2000, 2006), Veiga (2004) and Gadotti (2000). This study aimed to analyze and identify how the union between these two points can interfere qualitatively in the training of students. In the results it is considered that even not finding a link between the SMEs and the school of the PPP, the program has acceptance in the school community, fulfilling the role that it proposes: to assist children in vulnerability and monitoring of school learning situation. Key-words: More education program, political-pedagogical project, integral education. 


\section{Considerações iniciais}

Em busca de melhoria da qualidade da aprendizagem dos alunos, da diminuição das desigualdades educacionais, assim como para a valorização da diversidade cultural brasileira foi instituído o Programa Mais Educação - PME - pela portaria interministerial $\mathrm{n}$. 17/2007, de 24 de abril de 2007, e pelo decreto n. 7.083, de 27 de janeiro de 2010. Tratase de uma ação intersetorial entre as políticas públicas educacionais e sociais que integra as ações do PDE e que, na área da educação básica, tem propiciado a criação de uma escola para além da jornada regular, induzindo as redes a aderirem à ampliação do tempo na perspectiva da educação integral (Moll, 2012).

Nesse sentido, o trabalho, enquanto professora coordenadora do Programa Mais Educação, trouxe significativas reflexões acerca da qualidade, do contexto e dos objetivos de formação integral que a escola contempla no seu projeto político-pedagógico. Durante a inserção e atuação no mundo de trabalho conquistou-se a oportunidade de vivenciar as práticas e a organização cotidiana escolar e foi possível perceber a multiplicidade de saberes, temporalidades, valores e culturas que formam um único ambiente escolar. E, em vista disso, refletir sobre a importância de uma gestão escolar local, que considere a realidade singular de sua escola, a fim de contribuir eficazmente para a qualidade e melhoria de seu espaço e da formação de seus alunos.

Sendo assim, a experiência e o desafio presente na função exercida e o desejo de entrelaçar a prática profissional com o foco de pesquisa direcionou o interesse de estudo no sentido a repensar e compreender sobre a articulação entre o projeto políticopedagógico e a contribuição do Programa Mais Educação na formação do aluno.

Esta pesquisa se constituiu em um estudo de caso de cunho qualitativo, pois estudou a realidade de uma escola da rede pública de ensino do município de Santa Cruz do Sul/RS. Adotou-se como procedimento de coleta de dados a entrevista semiestruturada realizada com o diretor da instituição de ensino, professores responsáveis pelas oficinas ofertadas no Programa Mais Educação e pais de alunos participantes, além do levantamento de dados pela leitura e análise da legislação específica e da proposta pedagógica da escola.

Os resultados apontam que a educação integral no Brasil, a partir do Programa Mais Educação, ainda é uma política pública em construção. Contudo, pode-se considerar que mesmo não encontrando uma articulação entre o referido Programa e o PPP da escola, o PME demonstra ter aceitação na comunidade escolar e grandes contribuições na formação dos alunos, cumprindo, pois o papel que se propõe: atender as crianças em situação de vulnerabilidade, violência e acompanhamento e melhoria da aprendizagem escolar.

\section{Aspectos metodológicos}

De acordo com Almeida Júnior (1989) pesquisar, de modo geral, se trata de buscar uma informação que não se tem, mas que se deseja saber. Nesse sentido, o delineamento metodológico desta pesquisa subsidia-se na metodologia qualitativa com abordagem no estudo de caso.

Os estudos de pesquisa qualitativa diferem entre si quanto ao método, à forma e aos objetivos. Godoy (1995) ressalta a diversidade existente entre os trabalhos qualitativos e enumera um conjunto de características essenciais capazes de identificar uma pesquisa 
desse tipo: o ambiente natural como fonte direta dos dados e o pesquisador como instrumento fundamental; o caráter descritivo; o significado que as pessoas dão as coisas e à sua vida como preocupação do investigador; enfoque indutivo na análise dos dados.

Dessa forma, caracteriza-se por aprofundar o significado das ações e relações humanas em ambientes sociais e todos os participantes caracterizam-se como atores e construtores de conhecimentos e práticas que sirvam para intervir no problema levantado. A partir do momento que o pesquisador emerge em uma determinada realidade e estabelece uma relação dinâmica é possível compreender as relações práticas, no caso dessa investigação, o foco está relacionado à articulação do PPP com a execução do Programa Mais Educação e a contribuição na formação do aluno.

Já a abordagem que se refere ao estudo de caso apresenta características particulares que são destacadas por Lüdke; André (1986). Essas características são as seguintes:

1- os estudos de caso visam à descoberta. 2 - Os estudos de caso enfatizam a 'interpretação em contexto'. 3 - Os estudos de caso buscam retratar a realidade de forma completa e profunda. 4 - Os estudos de caso usam uma variedade de fontes de informação. 5 - Os estudos de caso revelam experiência vicária e permitem generalizações naturalísticas. 6 Estudos de caso procuram representar os diferentes e às vezes conflitantes pontos de vista presentes numa situação social. 7 - Os relatos de estudo de caso utilizam uma linguagem e uma forma mais acessível do que os outros relatórios de pesquisa. (p. 19)

Assim, volta-se ao nosso objeto de pesquisa: de que forma a articulação entre Programa Mais Educação e PPP contribui para a qualidade na formação dos estudantes? Podemos afirmar que só foi possível respondê-lo por meio da observação, atuação e intervenção junto aos atores envolvidos no Programa.

Para compreender o fluxo desse processo escolheu-se como procedimento de coleta de dados a entrevista semiestruturada. Tendo em vista fundamentar este estudo, optou-se, também, por um estudo documental, pelo qual se buscou analisar os documentos oficiais como os cadernos da série mais educação, a portaria interministerial n. 17, de 24 de abril de 2007, e o decreto n. 7.083, de 27 de janeiro de 2010, que norteiam as políticas públicas da educação integral e o Programa Mais Educação, assim como proposta pedagógica da escola. O estudo documental permitiu uma visão mais próxima da legislação e dos documentos do Ministério da Educação, que respaldam o Programa e auxiliou a compreensão sobre o seu desenvolvimento.

Ainda no que diz respeito aos processos de coleta de dados utilizou-se as informações oriundas das entrevistas semiestruturadas realizadas com o diretor, os seis professores responsáveis por ministrar as oficinas e com seis pais de alunos participantes do Programa Mais Educação no ano de 2015. Contudo, neste texto apresenta-se somente a concepção do diretor a fim de identificar e compreender as contribuições, influências, desafios e perspectivas do Programa Mais Educação; investigar e compreender de que maneira o Programa Mais Educação se articula com o projeto político-pedagógico e as atividades pedagógicas da escola; conhecer e analisar a concepção do diretor, professores e pais acerca do referido Programa; verificar e analisar de que forma 0 Programa Mais Educação contribui na formação dos estudantes. 


\section{O contexto da educação integral no Brasil}

Ao tratar-se sobre o Programa Mais Educação, inicialmente, não podemos deixar de mencionar sobre as raízes da educação integral no Brasil, fato que nos remete para os estudos de Anísio Teixeira, na década de 1950, quando tiveram início as primeiras tentativas de implantação de um sistema público de escolas com a finalidade de promover uma jornada escolar em tempo integral, consolidando a ideia de uma formação mais completa possível para o ser humano.

Segundo consta na escrita de vários autores, Nunes (2010), Ghiraldelli (2003), Anísio Teixeira, em uma das suas viagens pedagógicas para a Europa, embasou seus estudos e adotou o pensamento de John Dewey, ou seja, optou por uma alternativa que substitui os valores inspirados na religião católica que integra o corpo e a mente, o sentimento e o pensamento, o sagrado e o secular, em uma concepção de ensinar considerando agora o pensamento científico. Ao voltar da Europa transformou e operacionalizou seu projeto de reforma do ensino baiano e orientou mudanças na organização da educação estadual, pois acreditava que esse era o caminho para o processo de inovação e modernização da sociedade brasileira.

Na década de 1930 sua luta foi pela implantação de um sistema público de ensino, abrangente e de boa qualidade para o país. Nessa difícil tarefa Anísio Teixeira defendeu que a escola oferecesse às crianças um "programa completo de leitura, aritmética e escrita, ciências físicas e sociais, e mais artes industriais, desenho, música, dança e educação física [...] saúde e alimento à criança, visto não ser possível educá-la no grau de desnutrição e abandono em que vivia" (Teixeira, 1959, p. 78).

Nesse sentido, a proposta de Anísio Teixeira para o então ensino primário está fundamentada em uma concepção curricular baseada na formação completa do ser humano, pensando em uma construção de currículo que contemplam e desenvolvam atividades de cunho cognitivo, físico, intelectual e afetivo e que seja alicerçada em um horário que ofereça uma alimentação saudável. Ainda reforçando a sua visão de instituição escolar pública, pondera que a "escola eduque, forme hábitos, forme atitudes, cultive aspirações prepare, realmente, a criança para a sua civilização - esta civilização tão difícil por ser uma civilização técnica e industrial e ainda mais difícil e complexa por estar em mutação permanente" (Teixeira, 1959, p. 83).

A formação completa defendida por ele tem como base além da oferta de atividades intelectuais, artísticas, profissionais, físicas e de saúde, a formação de hábitos, valores e atitudes aspirando à formação para 0 progresso da civilização e o desenvolvimento científico e tecnológico no país.

Em 1950 é datada a primeira experiência de jornada ampliada na escola pública brasileira. Anísio Teixeira, secretário de Educação do Estado da Bahia, pôs em prática essa concepção de educação com a criação do Centro Educacional Carneiro Ribeiro implantado em Salvador, concretizando assim a primeira iniciativa e experiência de educação integral no Brasil. Nessa instituição os alunos receberiam em um turno o ensino tradicional e no outro a educação social e humanística. Segundo Guará (2006) o objetivo principal dessas iniciativas era oferecer ao aluno "a oportunidade de uma escolarização formal ampliada por um conjunto de experiências esportivas, artísticas, recreativas ou temáticas, em complementação ao currículo formal" (p.18). 
A educação integral vem sendo um tema interessante nas discussões dos últimos anos e está presente em importantes documentos como na legislação educacional brasileira, na Constituição Federal, no Estatuto da Criança e do Adolescente, na Lei de Diretrizes e Bases, no Plano Nacional de Educação e no Fundo Nacional de Manutenção e Desenvolvimento do Ensino Básico e de Valorização do Magistério.

Conforme o artigo 34, parágrafo $2^{\circ}$, da LDB 9394/96, o ensino fundamental será ministrado progressivamente em tempo integral, a critério dos sistemas de ensino. Já que as creches e pré-escolas podem ter papel relevante no combate à desnutrição e na melhoria dos indicadores de crescimento e desenvolvimento das crianças. No ensino fundamental, além dos aspectos de aprendizagem, o tempo integral contribuirá para impedir o trabalho infantil e afastar as crianças e adolescentes da criminalidade precoce, sendo um componente estratégico para o combate à pobreza e à exclusão social o que consolida essa tendência da educação brasileira ao ensino integral (Brasil, 2007).

É importante ressaltar que todas as iniciativas nesse campo, desde a primeira experiência, tiveram como defesa da expansão do ensino integral o fato de que é preferível, diante das desigualdades sociais, que a escola se responsabilize pelas crianças por mais tempo do que deixá-las na rua: "Em muitas famílias não há quem as mantenha afastadas da violência" (Moll, 2012, p. 24).

Uma alternativa para ampliar a jornada escolar seria a de por em prática o que propõe o PNE, que apresenta em sua proposta dez diretrizes, vinte metas e estratégias específicas para sua concretização, conduzidas para universalização e atendimento em todos os níveis e modalidades educacionais, sistematizadas a partir da visão sistêmica trazida em 2007 pelo Plano de Desenvolvimento da Educação - PDE.

A meta 6 do PNE diz que cabe "oferecer em tempo integral em $50 \%$ das escolas públicas de educação básica" e a estratégia 6.1 evidencia que deve-se estender progressivamente 0 alcance do programa nacional de ampliação da jornada escolar mediante oferta de educação básica pública em tempo integral, por meio de atividades interdisciplinares e de acompanhamento pedagógico, de forma que o tempo de permanência de crianças, adolescentes e jovens na escola ou sob sua responsabilidade passe a ser igual ou superior a sete horas diárias durante todo o ano letivo, buscando atender a, pelo menos, metade dos alunos matriculados nas escolas contempladas pelo programa.

Encontra-se em um dos principais documentos norteadores da criação e execução do Programa Mais Educação a ideia de que esta estratégia poderá

promover a ampliação de tempos, espaços, oportunidades educativas e o compartilhamento da tarefa de educar entre os profissionais da educação e de outras áreas, as famílias e diferentes atores sociais, sob a coordenação da escola e dos professores. Isso porque a Educação Integral, associada ao processo de escolarização, pressupõe a aprendizagem conectada à vida e ao universo de interesses e de possibilidades das crianças, adolescentes e jovens. (Brasil, 2009, p. 7)

Por esse prisma, em busca de estratégias para reverter o fraco desempenho dos alunos das escolas públicas revelados pelo Índice de Desenvolvimento da Educação Básica - Ideb - e para superar problemas graves da educação básica que perpetuam o ciclo de pobreza e analfabetismo, além de obstáculos à eficácia escolar, o governo federal 
lançou, em 2007, o Programa Mais Educação. Com o objetivo de atender as camadas estudantis em vulnerabilidade, obviamente, que nem se aproxima da proposta idealizada por Anísio Teixeira, mas procura fazer uma mediação frente aos problemas do analfabetismo, repetência, evasão, trabalho infantil, descaso familiar, baixa estima.

\section{O Programa Mais Educação}

O Programa Mais Educação foi instituído pela portaria interministerial n. 17/2007 e posteriormente regulamentado pelo decreto n. 7.083/2010. Integra ao Plano de Desenvolvimento da Educação - PDE -, cuja proposta visa à ampliação do tempo escolar e a organização curricular.

Dessa forma, por meio da portaria normativa interministerial n. 17, são estabelecidos os pressupostos legais, contemplando objetivos e finalidades para a implantação do Programa Mais Educação nas escolas públicas brasileiras:

\section{Dos objetivos}

Art. $1^{\circ}$ Instituir o Programa Mais Educação, com o objetivo de contribuir para a formação integral de crianças, adolescentes e jovens por meio da articulação de ações, de projetos e de programas do Governo Federal e suas contribuições às propostas, visões e práticas curriculares das redes públicas de ensino e das escolas, alterando o ambiente escolar e ampliando a oferta de saberes, métodos, processos e conteúdos educativos.

Parágrafo único. O programa será implementado por meio do apoio à realização, em escolas e outros espaços socioculturais, de ações socioeducativas no contraturno escolar, incluindo os campos da educação, artes, cultura, esporte, lazer, mobilizando-os para a melhoria do desempenho educacional, ao cultivo de relações entre professores, alunos e suas comunidades, à garantia da proteção social da assistência social e à formação para a cidadania, incluindo perspectivas temáticas dos direitos humanos, consciência ambiental, novas tecnologias, comunicação social, saúde e consciência corporal, segurança alimentar e nutricional, convivência e democracia, compartilhamento comunitário e dinâmicas de redes.

Na perspectiva do Programa Mais Educação cria-se uma política indutora de ampliação da jornada escolar, oportunizando aos Estados e Municípios condições de organizar a escola para a efetivação de educação integral. A partir da resolução n. 20 , de 6 de maio de 2011, que dispõe sobre a destinação de recursos financeiros, a escolas públicas municipais, estaduais e do Distrito Federal, com vistas a assegurar a realização de atividades de educação integral de forma a compor a jornada escolar, de, no mínimo, sete horas diárias.

O documento Programa mais educação - passo a passo (MEC, 2009) registra as atividades fomentadas pelo programa que foram organizadas nos seguintes macrocampos: acompanhamento pedagógico; meio ambiente; esporte e lazer; direitos humanos em educação; cultura e artes; cultura digital; promoção da saúde; educomunicação; investigação no campo das ciências da natureza; educação econômica.

A escola tem autonomia para escolher os macro-campos e as atividades que melhor se adéquam à realidade e à especificidade local. $\mathrm{Na}$ operacionalização do Programa define-se o público que será atendido. Alguns critérios são observados nessa seleção: estudantes que estão em situação de risco, vulnerabilidade social e sem assistência; 
estudantes que congregam seus colegas: incentivadores e líderes positivos - âncoras-; estudantes em defasagem série/idade; estudantes das séries finais da primeira fase do ensino fundamental - 4\%ํำ anos -, nas quais há uma maior evasão na transição para segunda fase; estudantes das séries finais da segunda fase do ensino fundamental - 8음 ou 9anos -, nas quais há um alto índice de abandono; estudantes de séries onde são detectados índices de evasão ou repetência.

Desse modo, a escola, articulada com o projeto político-pedagógico específico e em diálogo com sua comunidade, tem referências para definir quantos e quais alunos participarão das atividades ofertadas (Brasil, 2009). Nesse contexto, não há uma definição fechada sobre quem pode executar as atividades dos macro-campos e exercer a função de professor comunitário. As atividades podem ser acompanhadas por estudantes universitários em processo de formação específica nos macro-campos e com habilidades reconhecidas pela comunidade, por estudantes do ensino médio e estudantes da modalidade educação de jovens e adultos (Brasil, 2009).

A prioridade do Programa Mais Educação é o atendimento de escolas estaduais ou municipais de baixo Ideb, mas também utilizam como critérios escolas com índices igual ou superior a $50 \%$ de estudantes participantes do Programa Bolsa Família, escolas localizadas em territórios de vulnerabilidade social e escolas situadas em cidades com população igual ou superior a 18.844 habitantes. Nesse último encontra-se a escola de Santa Cruz do Sul em que realizamos essa pesquisa.

\section{União entre o projeto político-pedagógico e o Programa Mais Educação}

A escola pública investigada localiza-se no perímetro urbano do município de Santa Cruz do Sul, que está localizada na região central do Estado do Rio Grande do Sul. Funciona há 113 anos, sendo a escola de ensino médio mais antiga desse município. Atualmente, funciona nos três turnos tem uma demanda de mais de mil alunos distribuídos nas turmas de ensino fundamental, ensino médio e ensino técnico profissionalizante.

O Programa Mais Educação é executado nesta escola desde o ano de 2013. No ano de 2015 a escola atendeu no contra turno escolar alunos de $1^{\circ}$ ao $4^{\circ}$ ano da etapa dos anos iniciais do ensino fundamental matriculados no turno da tarde que foram contemplados com as atividades desenvolvidas pelo Programa Mais Educação, as quais ocorreram de segunda a quinta-feira no horário das $7 \mathrm{~h} 30 \mathrm{~min}$. até às $13 \mathrm{~h}$. Os alunos participantes das turmas de $1^{\circ}$ e $2^{\circ}$ ano participaram do Programa nas quartas e quintasfeiras, já os alunos do $3^{\circ}$ e $4^{\circ}$ ano foram atendidos nas segundas e terças-feiras.

Em 2015 a escola não precisou utilizar critérios para selecionar os alunos participantes devido à baixa procura das famílias e responsáveis, mas em anos anteriores uma das formas de seleção utilizadas foi a de considerar o fato de o aluno ser beneficiado pelo Programa Bolsa Família, além de saber se já realizava alguma outra atividade extraclasse e aos cuidados de quem ficava no turno em que não se encontrava na escola.

Talvez pelo fato de que no ano de 2015 as atividades do Programa foram ofertadas apenas dois dias consecutivos da semana houve uma diminuição na procura e até certa desistência por parte das famílias que inicialmente demonstraram interesse. Das cerca de 100 inscrições em torno de 70 que se efetivaram. 
A escola atendeu a cerca de 70 alunos que foram contemplados com atividades de acompanhamento pedagógico, dança, violão, handebol, taekwondo e horta escolar. Foi ofertado também as crianças participantes lanche e almoço diário. O quadro de professores comunitários foi composto por profissionais já formados que fazem parte da comunidade escolar e também por estudantes universitários.

Conforme se observa na pesquisa documental, a partir da análise da proposta pedagógica da escola, em nenhum momento foi relatado de forma clara a presença e o desenvolvimento de projetos que tem como base a educação integral nesse educandário. O que foi possível perceber é que o documento foi elaborado em 2009, o que ocasiona certo distanciamento e ausência de perspectiva do Programa Mais Educação, iniciado em 2013.

Frente a tal impasse, denota-se que o planejamento escolar realizado em 2009 não levou em conta questões atinente ao contexto nacional e mundial, deixando flexibilidade para inclusão de novas propostas a serem assumidas pela escola a médio e longo prazos, as quais possam ser capazes de atender e incluir os estudantes em vulnerabilidade. Isso só foi possível devido às condições propostas pelo governo federal, a partir de 2013, com a participação da escola no referido Programa.

A regulamentação da gestão democrática das escolas públicas, instituída pela LDB, demarca uma periodização em relação aos PPPs, dando autonomia aos estabelecimentos de ensino para elaborar, avaliar e atualizar seu projeto políticopedagógico. Não há um padrão único que oriente a elaboração deste projeto. Discutir o projeto político-pedagógico significa discutir a escola, levantar questões como: O que temos? O que queremos? Como queremos e o que fazer para atingir a escola que queremos.

O verdadeiro sentido da expressão autonomia escolar, segundo Lück (2000, p. 21), "consiste na ampliação do espaço de decisão, voltada para o fortalecimento da escola como organização social comprometida reciprocamente com a sociedade", ocorrendo dessa maneira uma autonomia participativa e efetiva, contribuindo verdadeiramente para a melhoria da qualidade do ensino. Assim, a construção desse importante documento passa pela autonomia da escola a fim de delinear sua própria identidade e definir as ações necessárias para formar o cidadão que deseja e para isso acontecer precisa ocorrer momentos de debates, de diálogos embasados a partir de reflexões coletivas.

Estudando mais profundamente a expressão projeto político-pedagógico nos deparamos com as afirmações de Veiga (2004), que ressalta o seu caráter intencional é o compromisso definido coletivamente, que o torna um projeto com características pedagógicas e políticas. Para a autora,

todo projeto pedagógico da escola é, também, um projeto político por estar intimamente articulado ao compromisso sociopolítico com os interesses reais e coletivos da população majoritária. É político no sentido de compromisso com a formação do cidadão para um tipo de sociedade [...] $\mathrm{Na}$ dimensão pedagógica reside a possibilidade da efetivação da intencionalidade da escola, que é a formação do cidadão participativo, responsável, compromissado, crítico e criativo. Pedagógico, no sentido de definir as ações educativas e as características necessárias às escolas de cumprirem seus propósitos e sua intencionalidade. (Veiga, 2004, p. 3) 
Neste sentido, a visão política deste projeto se reporta ao aspecto de sua construção coletiva, envolvendo uma comunidade participativa que, pelo envolvimento, ajuda a dar vida e a fazer com que o projeto tenha sentido no cotidiano da escola. Quanto ao pedagógico o Projeto assume o significado de dar direção à escola, assume o papel de norteador que ajuda na definição das diretrizes, o que pode ser feito, quais as ações que podem alterar a realidade ora enfrentada.

Para Veiga (2004, p 13), "o projeto político-pedagógico busca um rumo, uma direção. É uma ação intencional, com sentido explícito, com compromisso definido coletivamente". O PPP é mais que um mero documento obrigatório na escola, é a síntese de um processo permanente dentro dos muros escolares que apresenta quais os ideais e a intencionalidade da instituição que coletivamente define as prioridades e metas da escola e ao mesmo tempo a escolha de quais caminhos percorrer para se alcançar o sucesso e a qualidade na educação pública.

Nesse sentido, entrevista-se o diretor que já atua nessa função há 5 anos nessa mesma escola e agora no ano de 2016 exerce a função de vice-diretor dessa instituição de ensino.

Ao perguntar se o Programa Mais Educação contribui com a realidade da escola a resposta obtida foi positiva e ainda o diretor afirmou que "sim. O projeto bem orientado faz os alunos serem mais disciplinados, os pais passam a participar mais da vida escolar dos seus filhos e a criança desenvolve o gosto por novas atividades, como por exemplo, a horta" (depoimento do diretor).

Em outra pergunta da entrevista que contemplava a questão dos pontos positivos observados pelo diretor com o desenvolvimento do Programa ele cita alguns aspectos importantes como podemos observar a seguir: "Sim. A frequência dos participantes no projeto faz com que se tornem mais assíduos às aulas; a oficina de letramento ajuda a sanar as dificuldades escolares" (depoimento do diretor).

Considera-se que o PME nessa realidade escolar tem a aprovação dos pais e que os mesmos percebem mudanças significativas no comportamento dos seus filhos, assim como os próprios professores relatam o acompanhamento da evolução do grupo de alunos. O Programa Mais Educação é considerado, por muitas famílias, uma oportunidade única de seus filhos aprenderem um novo conhecimento e de estarem envolvidos na participação de atividades práticas relacionadas à música, arte e ao esporte. $O$ conceito de educação presente nesses projetos educacionais que envolvem a comunidade baseia-se no pressuposto de que aprender é conhecer, refletir e intervir no meio em que vive. O Programa Mais Educação enaltece, em seus objetivos e finalidades, o cultivo das relações entre escola e comunidade.

No que diz respeito ao foco dessa pesquisa, que é sobre a articulação do Programa Mais Educação com o projeto político-pedagógico, relacionam-se duas questões da entrevista com o diretor. A primeira foi: as atividades desenvolvidas no contraturno pelo Programa Mais Educação possuem articulação e/ou sintonia com as disciplinas e os conteúdos do turno regular? O diretor respondeu que "em parte porque depende da oficina e da série que o aluno se encontra" (depoimento do diretor). 
Sendo assim, acredita-se que as oficinas de horta e de acompanhamento pedagógico é que estão mais propensas a estabelecerem relações com o conteúdo trabalhado em sala de aula. Já as outras oficinas desenvolvidas, como violão dança, handebol e taekwondo relacionam-se mais ao desenvolvimento físico-motor e das habilidades de coordenação, ritmo, concentração das crianças.

A segunda questão é: o PPP tem relações e articulações com o trabalho executado nesse projeto na escola? A resposta do diretor é que "vem de encontro das propostas pedagógicas de aprendizagem e socializações” (depoimento do diretor).

De certo modo percebe-se, a partir da leitura e análise da proposta pedagógica, que em nenhum momento é citada a política de educação integral, tão pouco quais os ideais, as intencionalidades e os resultados que se pretende alcançar ao aderir e desenvolver o Programa Mais Educação desde o ano de 2013, ou seja, este documento está desatualizado com o contexto que a escola vivencia nos dias atuais, necessitando, pois de reformulação.

Para Gadotti (2000) o projeto pedagógico da escola é um processo nunca concluído, uma etapa em direção a uma finalidade que permanece como horizonte da escola. Em razão disso, ao procurar retratar a realidade da escola, o PPP nunca está pronto e acabado. Assim, assume um caráter contínuo, um processo de constante reconstrução, reflexões, rupturas e atualizações.

$\mathrm{Na}$ visão de Hengemuhle (2007) precisamos criar a cultura da construção e da presença viva do projeto pedagógico no cotidiano da escola, pois o sucesso de qualquer instituição e pessoa está vinculado à prática do planejado. É neste sentido que a adesão à construção do PPP não pode acontecer pela força da obrigatoriedade da legislação, mas com uma preparação do grupo, refletindo sobre a importância do projeto na perspectiva de ser útil não só para a vida da escola, mas para a de seus sujeitos. É uma prática educativa de sensibilização e de conquista dos que fazem parte da instituição escolar.

Ao questionar ao diretor se o Programa contribui na formação do aluno que a escola tem como objetivo formar, ele afirmou que sim e que "o cumprimento de regras, o respeito ao próximo, a partilha de jogos, lanches e da colheita da horta ajudem na formação do cidadão" (depoimento do diretor).

Isso vem de encontro com a função social da escola e o compromisso que tem com a sociedade de preparar as crianças para o exercício da cidadania. O Programa Mais Educação tem o significado de expandir, ampliar, alargar, estender algo que já existe, nesse caso a educação. Semelhante a concepção de educação que permeou os estudos e a filosofia do educador Anísio Teixeira, àquela educação que deve preparar integralmente o sujeito, no sentido de lhe oferecer as condições completas para a vida.

Nesse sentido, a função da escola extrapola o ensino e a transmissão de conteúdos que garantam o aprender a ler, escrever e contar. A função da escola avança para o campo da educação total do sujeito, no momento em que prioriza no seu currículo, não apenas os conteúdos tradicionais: da leitura, da escrita e das ciências exatas; contudo, quando oferta e oportuniza em seu trabalho pedagógico a transmissão de valores éticos e morais, do ensino das artes e da cultura, de experiências recreativas e esportivas, de hábitos de higiene e disciplina. 


\section{Conclusões}

Os debates em torno da educação integral existem desde o século 20 com destaque para o Manifesto dos pioneiros da educação nova e as propostas de Anísio Teixeira. $O$ Programa Mais Educação é uma tímida iniciativa governamental, ainda longe de se constituir no modelo sonhado por Anísio Teixeira que propugnava por uma política de Estado para todos. Porém, frente às condições sociais, culturais, econômicas e educacionais enfrentadas pelo Brasil, o PME se constitui numa política de caráter assistencial que objetiva reduzir as desigualdades sociais inerentes a sociedade capitalista.

Entretanto, a partir da análise dos dados, concluiu-se que o Programa Mais Educação tem aceitação e, segundo o ponto de vista dos entrevistados, apresenta reflexos positivos na qualidade de formação do aluno, por isso talvez encontre adesão positiva nas famílias que necessitam deixar seus filhos sob a guarda de alguém, servindo, pois a escola de agente responsável, também, por este papel.

Fica evidente que a participação no Programa influencia e melhora o desempenho da criança não só dentro da sala de aula, mas também em atividades fora da escola. A interação e a socialização, com a finalidade de aprender algo novo relacionado diretamente com a prática do aluno no meio em que está inserido, desperta o interesse e a curiosidade. Eles acabam transformando suas rotinas em função de estar envolvidos com o Programa, o que auxilia na busca do conhecimento.

Nas respostas obtidas em entrevista com o diretor percebe-se que o PME tem feito a diferença na vida dos alunos participantes e que tem reflexos no processo de ensino aprendizagem nas salas de aulas. Outro aspecto relevante citado é o fato de que os pais estão mais participativos na trajetória escolar de seus filhos, talvez por perceberem os benefícios que o Programa traz na rotina diária das crianças e o quanto elas demonstram interesse e prazer de estarem inseridas em um contexto de atividades diversificadas realizadas dentro e fora dos muros escolares, como é o caso de apresentações artísticas apresentadas à comunidade local em lugares públicos culturais da cidade. Também considerou importante que a escola, ao oportunizar atividades diferenciadas aos alunos no contra turno, contribui para as crianças sintam-se mais protegidas do mundo, na medida em que as afasta da rua e de possíveis situações de vulnerabilidade social.

No que trata da articulação entre o PME e a proposta pedagógica da escola não encontramos um ponto de união, pois logo que realizamos a leitura minuciosa do documento da escola constatamos um descompasso entre a proposta pedagógica instituída em 2009 e a proposta do Programa Mais Educação, que teve início no ano de 2013.

Conclui-se que a escola precisa reinventar-se para atender a esta demanda, iniciando por repensar, reorganizar suas metodologias, espaços, currículo, proposta pedagógica. Portanto, sugerimos revisão do projeto pedagógico para que possa estar de acordo com as normas escolares e com os projetos que a escola se propõe a oportunizar a sua comunidade escolar. 


\section{Referências}

ALMEIDA JÚNIOR, João Batista de. O estudo como forma de pesquisa. In: CARVALHO, Maria Cecília M. de (org.). Metodologia científica fundamentos e técnicas: construindo o saber. Campinas: Papirus, 1989, p. 97-118.

BRASIL. Lei n. 9.394, de 20 de dezembro de 1996. Lei de Diretrizes e Bases da Educação Nacional. Brasília, 1996. Disponível em <www.planalto.gov.br>. Acesso em 18 set. 2015.

BRASIL. Portaria Normativa Interministerial n. 17. Aprovada em 24 de Abril de 2007. Institui o Programa Mais Educação. Disponível em $<$ http://portal.mec.gov.br/arquivos/pdf/mais educacao.pdf>. Acesso em 15 ago. 2015.

BRASIL. Decreto n.. 7.083. Aprovado em 27 de janeiro de 2010. Dispõe sobre o Programa Mais Educação. Disponível em <http://www.planalto.gov.br/ccivil_03/_ato20072010/2010/decreto/d7083.htm>. Acesso em: 15 Ago. 2015.

BRASIL. Programa Mais Educação: Passo a passo (2009). Ministério da Educação. Disponível em <http://portal.mec.gov.br/dmdocuments/passoapasso maiseducacao.pdf $>$. Acesso em 20 ago. 2015.

BRASIL. Plano Nacional de Educação 2014-2024. Lei n. 13.005, de 25 de junho de 2014, que aprova o Plano Nacional de Educação (PNE) e dá outras providências. Brasília: Câmara dos Deputados, 2014.

ÉBOLI, Therezinha. Uma experiência de educação integral. Rio de Janeiro: Fundação Getulio Vargas/Instituto Nacional do Livro, 1971.

GADOTTI, Moacir. Perspectivas atuais da educação. Porto Alegre: Artes Médicas, 2000.

GHIRALDELLI, Paulo Jr. Filosofia e história da educação brasileira. São Paulo: Manoele, 2003.

GODOY, Arilda S. Introdução à pesquisa qualitativa e suas possibilidades. Revista de Administração de Empresas (RAE), v. 34, n. 2, 1995a, p. 57-63.

GUARÁ, Isa. É imprescindível educar inteligentemente. Cadernos CENCEP, n. 2, 2006, p. 15-24, Disponível em $<$ http://cadernos.cenpec.org.br/cadernos/index.php/cadernos/article/view/168>. Acesso em 19 set. 2015.

HENGEMUHLE, Adelar. Gestão do ensino práticas pedagógicas. Petrópolis: Vozes, 2007. LÜCK, Heloísa. Concepções e processos democráticos de gestão educacional. Petrópolis: Vozes, 2006.

LÜCK, Heloísa. Perspectivas da gestão escolar e Implicações quanto à formação de seus gestores. In: Gestão escolar e formação de gestores. Em Aberto. Brasília, v. 17, n. 72, 2000, p. 1-195.

LÜDKE, Menga; ANDRÉ, Marli Elisa Dalmazo Afonso de. Pesquisa em educação: abordagens qualitativas. São Paulo: Pedagógica e Universitária, 1986.

MOLL, Jaqueline et al. Caminhos da educação integral no Brasil: direito a outros tempos e espaços educativos. Porto Alegre: Penso, 2012.

MOLL, Jaqueline. 5 soluções para o ensino integral. Revista Nova Escola, ano IV, n. 21, 2012, p. 22-29.

NUNES, Clarice. Anísio Teixeira. Recife. Massangana, 2010. 
TEIXEIRA, Anísio Espínola. Centro Educacional Carneiro Ribeiro. Revista Brasileira de Estudos Pedagógicos. Rio de Janeiro, v. 31, n. 73, 1959, p. 78-84.

VEIGA, Ilma Passos Alencastro. Projeto político-pedagógico da escola: uma construção possível. Campinas: Papirus, 2004.

Fernanda Luiza Simon é licenciada em Pedagogia e especialista em Gestão Educacional pela Universidade Federal de Santa Maria. Professora na Escola Estadual de Educação Básica Estado de Goiás - Santa Cruz do Sul/RS.

Endereço: Rua Borges de Medeiros, 1099/403 - 96810178 - Santa Cruz do Sul - RS - Brasil.

E-mail: fernandasimon.ufsm@gmail.com.

Glades Tereza Felix é doutora em Educação pela Universidade Federal do Rio Grande do Sul e professora associada no Departamento de Administração Escolar do Centro de Educação da UFSM.

Endereço: Avenida Roraima, 1000 - Centro de Educação - 97015-970 - Santa Maria - RS - Brasil.

E-mail: gladesfelix@hotmail.com.

Recebido em 21 de setembro de 2016.

Aceito em 7 de novembro de 2016. 